\title{
Perceptions of inequity in the workplace: Exploring the link with unauthorised absenteeism
}

\author{
Authors: \\ Jessie Banks ${ }^{1}$ \\ Cynthia J. Patel \\ Mohammed A. Moola \\ Affiliations: \\ ${ }^{1}$ School of Psychology, \\ Howard College Campus, \\ University of KwaZulu-Natal, \\ South Africa \\ Correspondence to: \\ Cynthia Patel \\ Email: \\ patelc@ukzn.ac.za \\ Postal address: \\ School of Psychology, \\ University of KwaZulu-Natal, \\ King George V Avenue, \\ Durban 4041, South Africa \\ Dates: \\ Received: 07 July 2011 \\ Accepted: 14 Mar. 2012 \\ Published: 13 July 2012 \\ How to cite this article: \\ Banks, J., Patel, C.J., \& \\ Moola, M.A. (2012). \\ Perceptions of inequity in \\ the workplace: Exploring \\ the link with unauthorised \\ absenteeism. SA Journal \\ of Human Resource \\ Management/SA Tydskrif vir \\ Menslikehulpbronbestuur, \\ 10(1), Art. \#402, 8 pages. \\ http://dx.doi.org/10.4102/ \\ sajhrm.v10i1.402
}

C) 2012. The Authors.

Licensee: AOSIS

OpenJournals. This work

is licensed under the

Creative Commons

Attribution License.
Orientation: The focus of this study was the relationship between perceptions of inequity and specific withdrawal behaviours.

Research purpose: The purpose of the investigation was to explore possible relationships between workers' perceptions of inequity in the workplace, intentions toward withdrawal behaviour and unauthorised absenteeism.

Motivation for the study: There is very little South African research on the correlates of perceived inequity in the workplace. This study attempted to address the gap by exploring specific withdrawal behaviours as possible correlates of perceived inequity.

Research design, approach and method: Using a small-scale survey design, the researchers measured intentions towards withdrawal behaviour and recorded rates of absenteeism in a sample of 110 employees from a variety of automotive manufacturing companies in the KwaZulu-Natal area.

Main findings: The researchers did not find a relationship between perceptions of inequity and unauthorised absenteeism but did find one between perceptions of inequity and future withdrawal behaviours.

Practical/managerial implications: The high levels of perceptions of inequity amongst the workers and the finding that workers were more likely to engage in withdrawal behaviours in the future if they perceived unequal treatment in the workplace are worrying issues for the companies involved.

Contribution/value-add: The scale that the researchers developed to measure perceptions of inequity shows preliminary evidence of construct validity. The results suggest that employers need to monitor levels of perceived inequity especially in relation to future withdrawal behaviour.

\section{Introduction}

\section{Background to the study}

Employees are likely to take action if they feel that their employers are treating them unfairly compared to others in the workplace. In his equity theory, Adams (1965) proposed that employees compare what they invest in their work (inputs) with the rewards they receive (outcomes) with those of their fellow workers. If they perceive the ratio of inputs to outcomes as unequal, especially when they claim unfairness, workers could use negative strategies in their attempts to restore equity. They may avoid the aversive work conditions by resorting to absenteeism (De Boer, Bakker, Syroit \& Schaufeli, 2002), other behavioural 'withdrawal' responses like arriving late at work (Blau, 1994) or leaving work early.

Estimates of absenteeism in South Africa are that it costs organisations billions of rand every year (Johnson, 2007; Stokes, 2008). This represents a considerable loss to any organisation in terms of its effect on service delivery, loss of revenue, health and safety and the additional pressure on the staff members who are present at work (Munro, 2007).

\section{Trends from the research literature}

Riggio (2009) distinguishes between voluntary and involuntary forms of absenteeism. Whereas involuntary absenteeism refers to situations beyond the workers' control (like illness), voluntary absenteeism refers to the 'unauthorised' absence of workers. De Boer et al. (2002) refer to voluntary absenteeism as employees' avoidance of work.

Whilst absenteeism in general has received a great deal of research attention, studies on unauthorised absence have been rather limited. It is reasonable to expect that employees who 
have positive feelings about their jobs will be less likely to stay away than those with negative attitudes will be. Whilst there may be several causes of employee dissatisfaction at work, perceptions of inequity are particularly significant in South Africa given its history of apartheid. Although South African society and institutions have undergone significant transformation in recent years, unfair discrimination and inequalities remain deeply engrained in social structures, practices and attitudes (Van Wyk, 2002).

According to Van Yperen, Hagedoorn and Geurts (1996), the relationship between employees' perceptions of inequity, turnover and absenteeism has been a consistent finding in the literature. However, Arnold et al. (2010) point out that much of this research is out of date and researchers need to conduct further research.

The studies conducted over the last two decades, which focused on absence in relation to perceived inequity (DeBoeretal., 2002; Geurts, Schaufeli \& Rutte,1999; Van Yperen et al., 1996), have not distinguished between authorised and unauthorised absence. Apart from the Van Yperen et al. (1996) study, the investigations have not included Adam's comparison in their measures of unfairness or inequity. Bolino and Turnley (2008) emphasise the need to examine how other parts of the world apply equity theory, which originated in the United States of America (USA).

Because of the shortcomings of past studies and the need to examine Adam's equity model amongst workers outside of the USA, the researchers designed the present study as an exploration of the relationship between perceptions of inequity, with specific reference to a 'comparison other', unauthorised absenteeism and intended withdrawal behaviours. These withdrawal behaviours include employees' intentions to stay away, to arrive late at work and to leave early when faced with inequity.

In line with Adam's equity theory, the researchers developed a scale that measures perceptions of inequity for the purpose of this study.

\section{Adams' equity theory}

Adams' equity theory (Adams, 1965) is a model of motivation that explains how people strive for fairness and justice in social exchanges. This theory proposes that perceived inequity is a motivational force. The conditions that are necessary to produce equity or inequity use an employee's perceptions of inputs and outcomes as their basis. The ratio of inputs to outcomes becomes a process of social comparison in which each employee compares his or her inputs and outcomes to those of another employee (Weller, 1995). Adams (1965) describes this other person as the 'comparison other.'

There are usually several inputs. They include acceptance of responsibility, job knowledge, experience, education, personal involvement with work, dedication, age, effort, seniority, time, skill and performance. Outcomes usually consist of rewards or benefits like pay, promotional opportunities, praise, prestige, recognition, interpersonal relations with supervisors and co-workers, status, increases in salary and fringe benefits (McKenna, 2000; Northcraft \& Neale, 1994).

When inputs are commensurate with outcomes, the employee sees the situation as equitable. In this equitable (fair) situation, the employee is content and will not take any action to achieve equity. However, when a situation is inequitable, an employee perceives that he or she is receiving fewer outcomes than the 'comparison other' is receiving for his or her inputs even though both are contributing the same inputs (Adams, 1965; Northcraft \& Neale, 1994).

The characteristics (age, gender, race, tenure and educational level) of the employee who perceives a situation (CohenCharash \& Spector, 2001) may also influence his or her perceptions of inequity. When he or she perceives inequity, the employee will usually experience a state of cognitive dissonance (or feelings of psychological discomfort). This motivates the employee to reduce the discomfort (Weller, 1995). The tension this cognitive dissonance causes varies. The greater the tension, the greater is the motivation to act in order to reduce it and achieve equity (Adams, 1965; Geurts et al., 1999).

Slocum and Hellriegel (2009) list possible responses to perceived inequity:

- modify one's inputs or outcomes

- distort or modify perceptions of the self or of the 'comparison other'

- change the 'comparison other'

- move to a new reference group

- change the outcomes

- get the 'comparison other' to change his or her inputs and outcomes

- leave the organisation.

Initially, 'leaving the place of employment' meant resigning from the organisation. However, it includes withdrawing through absenteeism. The literature (Aldag \& Brief, 1981; Geurts, Buunk \& Schaufeli, 1994; Geurts et al., 1999; Northcraft \& Neale, 1994; Van Yperen et al., 1996) supports the option of temporary withdrawal from the organisation in response to perceived inequity. Absenteeism, as a withdrawal reaction to perceived inequity, is a withdrawal from work obligations and from the organisation in order to reduce the employee's inputs and weaken the exchange relationship with the organisation (De Boer et al., 2002). Blau's (1994) finding of a relationship between chronic lateness, unauthorised absence, leaving work early, poor work involvement and job satisfaction supports the pattern of withdrawing from work. Because the literature sees workers' perceptions of inequity as an antecedent to (low) job satisfaction (Khalifa \& Truong, 2010), one expects that it also relates to the withdrawal behaviours mentioned above.

Although Adam's equity theory has received some criticism, it is one of the most significant theories in the field of organisational behaviour (Bolino \& Turnley, 2008). 


\section{Absenteeism and other forms of withdrawal behaviour}

Absenteeism is disruptive. It relates to non-attendance when employees are expected or scheduled to be at work. According to Riggio (2009, p. 226), one associates absenteeism with organisational commitment because employees who have positive feelings about their jobs and organisations 'should be less likely to be absent from work' than are those with negative attitudes about their jobs. If employees perceive an inequitable situation in the workplace, they are motivated to take behavioural and/or cognitive actions to restore equity to the situation (Adams, 1965). Therefore, it is possible that the employees with negative feelings about their jobs because of their perceptions of inequity will resort to 'unauthorised absence'.

For the purposes of this study, voluntary or unauthorised absenteeism is 'the non-attendance of employees for scheduled work when they are expected to attend' (Huczynski \& Fitzpatrick, 1989, p. 3). This excludes absenteeism because of personal illness, family death, weather or transport problems.

There are other forms of employee disengagement from the work situation. An example is employee lateness (Blau, 1994). However, very few studies have examined it in relation to perceived inequity. Most companies do not keep accurate records of employee lateness. Therefore, the researchers examined it as an intended behavioural option if employees perceived unfairness in the workplace. Therefore, in addition to actual unauthorised absenteeism, the present study examined withdrawal intentions like reporting late for work, leaving work early and taking unauthorised leave in the face of perceived unfairness.

\section{Empirical review}

\section{Absenteeism and perceived inequity}

As Arnold et al. (2010) noted, researchers conducted most of the studies on equity theory in the 1960s and 1970s. From the review of the relevant literature, which links equity theory to withdrawal behaviours in the workplace, one can see that much of the research is out of date and there have been very few studies in recent years.

Dittrich and Carell (1979) examined whether job satisfaction and/or perceptions of inequitable treatment relate to employee behaviours like absenteeism and turnover. They found that employee perceptions of inequitable treatment were stronger predictors of absence and turnover than low job satisfaction was.

Geurts et al. (1999) used a sample of health care professionals to focus on perceived inequity in relation to turnover and absenteeism. Their finding of a direct link between inequity and absenteeism is relevant to the present study. They concluded that one could regard absenteeism as a direct withdrawal reaction to perceived inequity. However, their measure of inequity in the employment relationship dealt with employees' perceptions of the correspondence between their rewards (outcomes) compared to their investments (inputs) and did not include reference to the 'comparison other' when assessing inequity.

Hirschfeld, Schmitt and Bedeian (2002) used a similar measure in which they asked civil service clerical employees to rate their perceptions of the correspondence between their performance on the job and their reward expectations. They found that the employees, who thought they received especially low performance rewards and who thought that their jobs required a variety of high skills and important tasks, were likely to be absent more often.

Van Yperen et al.'s (1996) measure of inequity required participants to compare themselves to fellow workers on 14 aspects of their jobs. However, it consisted of a single question that asked participants to rate their feelings about their jobs compared to those of other employees in the company. Their argument for using this strategy was that there is a strong relationship between an overall assessment of inequity and specific aspects of jobs. Their findings revealed a significant relationship between perceived inequity and absenteeism in their sample of Dutch blue-collar workers. However, some employees who perceived that their co-workers were intolerant about absenteeism were less likely to report being sick, despite their perception of inequity in the workplace.

The scale that De Boer et al. (2002) used to assess distributive fairness in their study of security guards in Belgium was more consistent with Adam's model because it incorporated the element of a 'comparison other' in estimating perceived unfairness on issues of 'workload', 'effort invested at work' and 'willingness to help a colleague'. The authors found that perceived unfairness at work was a significant factor that linked to future absence behaviour. However, they did not find evidence to support a direct relationship between perceived unfairness and absence frequency. They explained this inconsistent finding by pointing to the possible influence of Belgium's strict absence policy and the unique nature of the exchange relationship between the workers and the organisation.

In general, these studies support the equity theory claim that, when employees perceive an inequitable situation, it causes cognitive dissonance. In order to restore equity, employees could use the response of being absent from work. However, because none of the studies distinguish between 'voluntary' and 'involuntary' absence, it is difficult to infer that one can expect the same pattern of behaviour in the face of perceived inequity. Researchers have suggested other withdrawal behaviours that deal with perceived unfairness. However, there has been no research that specifically examines unauthorised absenteeism and other withdrawal responses, like arriving late and leaving early.

Although researchers have conducted several studies that investigate the relationship between absenteeism and 
perceived inequity in the workplace, more research is necessary. Bolino and Turnley (2008), note that it is important to examine how one can apply equity theory, an idea that originated in the USA, to other parts of the world.

The literature review did not reveal any South African studies that specifically explored the relationship between Adams' equity theory and absenteeism in the workplace. Therefore, it is necessary to research equity theory and its propositions in South Africa's diverse and complex workforces. According to Stepina and Perrewe (1991), areas that require further research involve the theory's major components about feelings of inequity and their subsequent employee reactions. It is also important to measure inequity with specific reference to the 'comparison other' in Adam's theory.

In response to the lack of previous research on distinguishing between voluntary and involuntary absence, this study sets out to explore the relationship between the perception of inequity and unauthorised absenteeism in a specific setting. The researchers designed this study to investigate whether the actual and intended responses of absenteeism link to levels of perceived inequity in the workplace. In the context of an unstable economy, the researchers chose the automotive industry, which has experienced a number of job losses and has threatened to downsize (Beires, n.d.), as the site for this study.

\section{Aim and hypothesis of the study}

The main aim of the study was to explore the relationship between perceived inequity and unauthorised absenteeism. The researchers hypothesised that the greater the workers' perceptions of inequity, the greater was the likelihood that they would resort to unauthorised absence from work.

\section{Research design \\ Research approach}

The researchers used a small-scale cross-sectional survey design for this study. It followed the quantitative tradition in which they measured variables (perceptions of inequity and absenteeism) and looked for relationships between them.

\section{Research method}

\section{Research participants}

Of the 18 component manufacturing companies in KwaZuluNatal, a province of South Africa, which the researchers approached, 11 agreed to participate in the study. The researchers asked each organisation to select 10 employees randomly from the unskilled, semi-skilled and lower-skilled categories. This yielded a sample of 110 workers. Fiftyseven men (52\%) and 53 women (48\%) made up the sample. There were $72(70 \%)$ workers in the 20 to 40 age group. Of the sample, $40(36 \%)$ were Black, $21(19 \%)$ were Coloured, 32 (29\%) were Indian, and 17 (16\%) were White. Most (71\%) had a secondary school education and $66 \%$ had been in the company's employ for fewer than five years.

\section{Measuring instrument}

The questionnaire the researchers developed for this study consisted of two parts. Section A contained biographical data about age, gender, ethnic group, number of years employed in the company and level of education. Section B consisted of two parts.

Part 1 (10 items) aimed to identify workers' perceptions of their inputs (five items) compared to those of their fellow workers and their outcomes (five items) compared to those their fellow workers received for similar work they performed at their places of work. An example of an input item was 'I put in more effort for the work I do for my organisation than my co-workers'. An example of an outcome item was 'I receive less recognition (appreciation, thanks and acknowledgement) from my supervisor than my co-workers who perform similar tasks'.

The researchers drew the content of the items mainly from Adam's equity theory and Gordon's (1987) suggestions on how one should address inequity. The researchers modified and adapted the items they included in the questionnaire from the experiential exercise that Gordon (1987) developed. The original scale consisted of 14 items, but the researchers reduced them to 10 after their pilot study uncovered four problematic items.

Whilst this measure does not use the ratio of the outcomes to the inputs of employees compared to 'comparison others' (Adams, 1965), the researchers designed it to determine the extent to which employees perceive inequity or equity in the workplace by comparing their inputs and outcomes to those of the 'comparison others'. The response format ranged from 4 (strongly agree) to 1 (strongly disagree). The researchers reverse coded responses to the outcome items. Therefore, the higher the scores on this scale, the greater were the perceptions of inequity.

Part 2 contained three items that measured behavioural intentions (to come late to work, to leave work early or to stay away from work) in the event of perceived unfair treatment in the work place.

\section{Research procedure}

The researchers received ethical clearance from the Higher Degrees Committee of the Faculty of Humanities, Development and Social Science (HDSS), University of KwaZulu-Natal, before administering the questionnaires. Because they drew their sample from across KwaZulu-Natal, it was necessary to post questionnaires, together with detailed instructions, so that human resource managers could administer the questionnaires to the selected workers. The first author administered the questionnaires personally in the companies closer to central Durban.

After completing the questionnaires, the participants either handed them back to the first author on the same day or sent them back to the first author by post. All 
participants had to sign an informed consent form before participating in the study.

The researchers computed the participants' rates of absenteeism for a period of three months before the study from employees' absenteeism records. They developed four categories: sick leave, official leave, compassionate or family leave and unauthorised absence.

\section{Statistical analysis}

The researchers used SPSS version 15 to analyse the data. Although a preliminary analysis of the distribution of the item responses for the sample yielded a skewed distribution, the researchers attempted an exploratory analysis of the underlying structure of the items. According to Tabachnick and Fidell (2007), the requirement of normality need not apply if the aim of the factor analysis is to describe the summarised relationship between a set of variables.

Although the distribution was not normal, the analysis could have some value. Therefore, the researchers subjected the 10 items of the instrument they constructed to measure perceptions of inequity, in terms of inputs and outcomes, to an exploratory principal components analysis using varimax orthogonal rotation. They used Kaiser's criterion, of retaining those items with eigenvalues greater than 1 , to extract the two factors. They accounted for $61 \%$ of the variance.

The researchers used Steven's (1986) recommendation to assess the significance of the item loadings. This involves multiplying the critical value of $r$ by 2 in order to arrive at a more stringent level of significance. Because the critical value for a sample of about 120 is $.236(p<.01)$, the adjusted critical value is .472 . The researchers retained only the items with factor loadings that exceeded the adjusted critical value.

Table 1 presents the significant factor loadings.

Factor 1 (five items) refers to the input items whilst factor 2 consists of the four output items. The researchers found that the last outcomes item had common variance for both factors. Therefore, they excluded it from further analysis. They treated the two factors as subscales in the subsequent analyses. They analysed the items to determine their internal consistency.

This examination yielded promising results. The input subscale yielded an alpha of .80, the outcomes subscale an alpha of .83 and the internal consistency index for the total was .87 . The three items that measured behavioural intentions yielded an alpha of .87 .

The researchers used Pearson $r$ to examine the correlations between perceived inequity, absenteeism and withdrawal intentions.

\section{Results}

The researchers present the descriptive statistics for the measures of perceived inequity, for the items that measure intended withdrawal behaviour and the employees' rates of absenteeism. The correlations between the variables follow.
Table 2 gives the means and standard deviations for the inputs and outcomes subscales.

The highest possible score on the inputs subscale is 20. This means that the mean (15.28) for the sample is relatively high. This shows that the sample as a whole indicated that, compared to their fellow workers, they spend more time, energy and effort at work and have better skills and more experience.

On the outcomes subscale, the mean of 12.33 is relatively high given the highest possible score of 16 . The workers report that they receive fewer rewards and recognition for the work that they do compared to their fellow workers.

Table 3 presents the results on the 'intended withdrawal' items.

The researchers combined the agree and strongly agree responses into an agree category and the disagree and strongly disagree responses into a disagree category. More than two-thirds of the sample disagreed that they would choose the strategy of arriving late at work or leaving work early and just under two thirds agreed that they would stay away from work if they felt their organisation was treating them unfairly compared to their co-workers.

Table 4 contains the absenteeism rates for the three months before the study.

Table 4 shows that more than two-thirds $(67.3 \%, n=74)$ of the sample had not taken any unauthorised days off from work in the three months before the study. However, for the rest of the sample $(n=36)$, the total number of days of unauthorised leave the employees took was 118 days. This is an average of 3.28 days per worker.

To achieve the aims of the study, the researchers correlated the inputs and outcomes subscale scores with the number of

TABLE 1: Factor loadings of items that measure perceptions of inequity.

\begin{tabular}{lll}
\hline Item type & Item & Loading \\
\hline Factor 1: Inputs† & Experience & .739 \\
& Effort & .752 \\
& Years employed & .694 \\
& Skill & .646 \\
Factor 2: Outcomes $\$$ & Time & .633 \\
& Recognition & .591 \\
& Income & .738 \\
& Bonuses & .819 \\
& Benefits & .889 \\
\hline
\end{tabular}

$\dagger, \alpha=.80$.

$\sharp \alpha=.83$

TABLE 2: Descriptive statistics for the 'inputs' and 'outcomes' subscales.

\begin{tabular}{lllll}
\hline Item type & $\begin{array}{l}\text { Number of } \\
\text { items }\end{array}$ & $\begin{array}{l}\text { Subscale } \\
\text { mean }\end{array}$ & SD & $\begin{array}{l}\text { Item } \\
\text { mean }\end{array}$ \\
\hline Inputs & 5 & 15.28 & 3.21 & 3.05 \\
Outcomes & 4 & 12.33 & 2.77 & 3.09 \\
\hline
\end{tabular}

SD, standard deviation. 
TABLE 3: Responses to the items that measure intended withdrawal behaviours

\begin{tabular}{|c|c|c|c|c|c|c|c|}
\hline \multirow[t]{2}{*}{ Item } & \multirow[t]{2}{*}{ Number of items } & \multicolumn{2}{|c|}{ Agree } & \multicolumn{2}{|c|}{ Disagree } & \multirow[t]{2}{*}{ Item mean } & \multirow[t]{2}{*}{ SD } \\
\hline & & Number & Percentage & Number & Percentage & & \\
\hline Late to work & 1 & 43 & 39.1 & 67 & 60.9 & 2.35 & 1.05 \\
\hline Leave early & 1 & 41 & 37.3 & 69 & 62.7 & 2.35 & 1.04 \\
\hline Stay away & 1 & 64 & 58.2 & 46 & 41.8 & 2.8 & 1.07 \\
\hline
\end{tabular}

SD, standard deviation.

days of unauthorised absence and the individual items of the 'intended withdrawal' subscale.

Table 5 presents the results.

Table 5 shows that the researchers found no significant relationship between perceptions of inequity, as measured by the inputs and outcomes subscales, and unauthorised absence.

However, they did find significant positive relationships between unauthorised absence and each item of the behavioural intention scale. This means that the greater the agreement that the employees would engage in withdrawal behaviours (arriving late, leaving early or taking unofficial days off) if they perceived unfairness, the greater was the likelihood that they would actually stay away from work.

The researchers found that the inputs and outcomes subscales had a significant positive correlation with the items of the behavioural intentions scale.

\section{Discussion}

The main aim of the study was to explore the relationship between perceived inequity and unauthorised absence from work in a sample of automotive workers. Because there has been very little research on this topic in South Africa, the researchers hoped that this study would provide the impetus for further investigation.

\section{Perceived inequity and unauthorised absenteeism}

Although the respondents reported high levels of inequity in the workplace, both in terms of their perceptions of the inputs and outcomes compared to their fellow workers, there was no relationship between this perceived inequity and actual unauthorised absence from work.

These findings were inconsistent with those of Geurts et al. (1999) and Van Yperen et al. (1996), who found a link between perceptions of inequity and absenteeism. However, De Boer et al. (2002) also failed to find a relationship.

Unlike these investigations, the present study distinguished between unauthorised absenteeism and sick leave in an attempt to isolate voluntary absenteeism. More than two-thirds of the sample $(n=74)$ had not been absent from work (unauthorised absence) in the three months before the study. Seventeen per cent $(n=19)$ had been away for one or two days, whilst the rest $(n=17)$ had taken unauthorised leave for between three and eight days.
Given the unstable economic situation and the difficulty with finding employment, especially for lower-skilled workers, this pattern is not surprising. It is possible that most of them choose to endure the differential treatment that they feel that they receive compared to their colleagues rather than risk jeopardising their employment by staying away.

Beires (n.d.) has cautioned about the high probability of even more job losses in the automotive industry in the future. Taylor, Moghaddam, Gamble and Zellerer (2001) suggest that passive acceptance is one of the broad characteristics of a group response to perceived inequality. The authors suggest that, where group members perceive unfairness (as with the present sample), they have low status and feel that they have limited control. Therefore, they tend to feel helpless and accept their situation.

Another explanation for the finding, that most employees have not resorted to withdrawal behaviours in the form of unauthorised absence, is that it could link to companies' levels of tolerance in their absence policies, as De Boer et al (2002) suggested. It is possible that those who have not stayed away work for companies that have strict rules about absence whilst those who have taken unauthorised leave may work for companies that are more lenient.

Although more than two-thirds of the sample (67.3\%) were not absent from work in the three months before the study, the unauthorised absenteeism rate of the remaining 36 workers is a definite cause for concern. These workers were absent for a total of 118 days during the three-month period. Factors other than perceptions of inequity may be operating in their work environments and may explain their unauthorised absence. De Boer et al. (2002) noted that previous studies have reported links between work dissatisfaction and low work commitment with absenteeism.

\section{Perceived inequity and behavioural intentions}

The researchers did not find a relationship between employees' actual absence during this time and their reports of inequity. However, the employees' stated intention to withdraw by arriving late, leaving early and staying away

TABLE 4: Unauthorised absenteeism rates for the sample for a three-month period.

\begin{tabular}{lll}
\hline Number of days absent & Frequency & Percentage \\
\hline 0 days & 74 & 67.3 \\
1-2 days & 19 & 17.3 \\
3-4 days & 7 & 6.3 \\
5-6 days & 5 & 4.5 \\
7-8 days & 5 & 4.5 \\
\hline Total number of days & $\mathbf{1 1 0}$ & - \\
\hline
\end{tabular}


TABLE 5: Correlations between inputs, outcomes, intended withdrawal behaviours and unauthorised absenteeism.

\begin{tabular}{|c|c|c|c|c|c|}
\hline Item & Outcomes & Late to work & Leave work early & Stay away from work & Unauthorised absence \\
\hline Inputs & $.63 * *$ & $.35 * *$ & $.31 * *$ & $.37 * *$ & .13 \\
\hline Outcomes & - & $.27 * *$ & $.25 * *$ & $.30 * *$ & .08 \\
\hline Late to work & - & - & $.77 * *$ & $.49 * *$ & $.22 *$ \\
\hline Leave work early & - & - & - & $.58 * *$ & $.19 *$ \\
\hline Stay away from work & - & - & - & - & $.22 *$ \\
\hline Unauthorised absence & - & - & - & - & - \\
\hline
\end{tabular}

$*, p<0.05 ; * *, p<0.01$

from work suggests that this could be a source of concern for the future in the automotive companies involved in the study.

The more employees perceived levels of inequity, the greater was their agreement that they would consider engaging in withdrawal behaviours by staying away, leaving work early or coming to work late.

The researchers found significant correlations between employees' perceptions of inequity, both in their inputs and their outcomes, and each of these intended withdrawal behaviours. The more employees felt that they were investing a greater amount of time and effort in their work than their colleagues were, the more likely were they to engage in withdrawal behaviours if they felt their organisation was treating them unfairly.

Therefore, whilst it may be tempting to conclude that most employees have adopted a passive acceptance of the inequitable situation by not resorting to unexcused absence, their intended actions suggest different outcomes in the longer term. Researchers need to investigate whether these levels of disenchantment about perceived unfairness in the work situation may link, in the short-term, to other negative outcomes like reduced productivity, 'go-slow' strategies and increased interpersonal conflicts in the work situation. They may resort to other tactics as a way of expressing their dissatisfaction and perceptions of unfairness in order to maintain a level of equilibrium.

Various studies (De Boer et al., 2002; Geurts et al., 1999; Joshi, 1989; Khalifa \& Truong, 2010) report that employees can display negative reactions to inequity. These could include theft, reduced productivity, low levels of motivation and job satisfaction, high levels of employee burnout and turnover. In the current economic climate, it is possible that the reason employees do not use unauthorised absence, as a way of dealing with perceived inequity, is that they have no choice. They must accept the inequity or lose their jobs.

Levels of involvement in the work situation may have a moderating effect on actual behaviour (Van Yperen et al., 1996). De Boer et al. (2002) pointed out that it is important to assess workers' relationships with their organisations. If workers feel that their employers are failing to fulfil their end of the psychological contract, then it is likely that they will develop negative attitudes.

In the context of the present study, the stated withdrawal intentions of almost $40 \%$ of the sample to arrive at work late and leave work early, together with almost $60 \%$ who indicated that they would stay away from work, are examples of negative reactions that link to perceptions of inequity.

\section{Recommendations}

The findings of this study do not support the main hypothesis that there is a relationship between perceptions of inequity and unauthorised absenteeism. Nevertheless, the study highlights the high levels of unfairness that workers seem to perceive. Future research needs to consider other factors (personal, economic and contextual) that mediate the relationship between perceived inequity and actual withdrawals. These may include worker commitment, the absence policies of the companies involved or the lack of alternative work options.

The tendency for workers to admit that they would adopt withdrawal behaviours in the context of inequity is a source of some concern. In this regard, De Boer et al. (2002) emphasise the importance of communication between workers and their managers to identify and address the imbalance between workers' investments and outcomes or rewards.

This could be through one-on-one discussions with workers or routine surveys of employees' concerns. Johnson's suggestion (2007), that companies adopt a return-to-work policy in which workers must report to their supervisors as soon as they return to work after sick leave could also be applied to unauthorised absence. This could identify problem issues. Organisations could follow these up with appropriate interventions that aim to maintain the well-being of workers and their organisations.

Whilst the results of the factor analysis offer some evidence for the construct validity of the items the researchers used in the study, and whilst the internal consistency of the items appears to be good, further research is needed to test the reliability and validity of the instrument.

\section{Limitations of the study}

The period of three months that the researchers used in the study may be too short and may not have allowed them to observe absenteeism thoroughly as a possible response to perceived inequity.

This was a once-off cross-sectional study. It is likely that transient issues influenced the participants' responses. Longitudinal studies, where researchers track employees 
over a longer period, will allow them to assess whether perceptions of inequity persist and whether these attitudes link to unauthorised absence from work.

One needs to consider the possibility that the items that measured perceptions of inequity were suggestive or leading in the way they were phrased and resulted in biased answers.

The limited sample was another issue that makes it difficult for one to generalise the findings beyond the present group.

\section{Acknowledgements Competing interests}

The authors declare that they have no financial or personal relationship(s) that may have inappropriately influenced them when they wrote this paper.

\section{Authors' contributions}

This paper used the short dissertation that J.B. (University of KwaZulu-Natal) completed in partial fulfilment of her Master's degree in industrial psychology as its basis. M.A.M. (University of KwaZulu-Natal) supervised the dissertation. C.J.P. (University of KwaZulu-Natal) conducted the statistical analysis. J.B. (University of KwaZulu-Natal) prepared the first draft whilst C.J.P. (University of KwaZuluNatal) was chiefly responsible for further revisions of the manuscript. M.A.M. (University of KwaZulu-Natal) assisted with the process.

\section{References}

Adams, J.S. (1965). Inequity in social exchange. In L. Berkowitz (Ed.), Advances in experimental social psychology, (pp. 267-299). New York: Academic Press.

Aldag, R.J., \& Brief, A.P. (1981). Managing organisational behaviour. Minnesota: West Publishing.

Arnold, J., Randall, R., Patterson, F., Silvester, J., Robertson, I., Cooper, C. et al. (2010) Work Psychology: Understanding human behaviour in the workplace. London: Prentice-Hall.

Beires, L. (n.d.). Should the South African automotive sector receive a government bailout? Research and Development Unit. Dept. of Economic Development and Tourism. Retrieved March 26, 2011, from http://www.kznded.gov.za/Portals/0/ Should\%20the\%20motor\%20industry\%20receive\%20a\%20bailout.pdf

Blau, G. (1994). Developing and testing a taxonomy of lateness behaviour. Journal of Applied Psychology, 79(6), 959-970. http://dx.doi.org/10.1037/0021-9010.79.6.959

Bolino, M.C., \& Turnley, W.H. (2008). Old faces, new places: equity theory in crosscultural contexts. Journal of Organizational Behavior, 29, 29-50. http://dx.doi. org/10.1002/job.454

Cohen-Charash, Y., \& Spector, P.E. (2001). The role of justice in organizations: A metaanalysis. Journal of Organizational Behavior and Human Decision Processes, 86(2) 278-321. http://dx.doi.org/10.1006/obhd.2001.2958
De Boer, E.M., Bakker, A.B., Syroit, J.E., \& Schaufeli, W.B. (2002). Unfairness at work as a predictor of absenteeism. Journal of Organizational Behavior, 23(2), 181-191. http://dx.doi.org/10.1002/job.135

Dittrich, J.E., \& Carrell, M.R. (1979). Organizational equity perceptions, employee job satisfaction and departmental absence and turnover rates. Organizational Behavior and Human Performance, 24, 29-40. http://dx.doi.org/10.1016/00305073(79)90013-8

Geurts, S.A., Buunk, B.P., \& Schaufeli, W.B. (1994). Social comparisons and absenteeism: A structural modeling approach. Journal of Applied Social Psychology, 24, 18711890. http://dx.doi.org/10.1111/j.1559-1816.1994.tb00565.x

Geurts, S.A., Schaufeli, W.B., \& Rutte, C.G. (1999). Absenteeism, turnover intention and inequity in the employment relationship. Work and Stress, 13(3), 253-267. http://dx.doi.org/10.1080/026783799296057

Gordon, J.R. (1987). A diagnostic approach to organizational behaviour. (2nd edn.). Massachusetts: Allyn and Bacon.

Hirschfeld, R.R., Schmitt, L.P., \& Bedeian, A.G. (2002). Job-content perceptions, performance-reward expectancies, and absenteeism among low-wage publicsector clerical employees. Journal of Business and Psychology, 16(4), 553-564. $\mathrm{http}: / / \mathrm{dx}$.doi.org/10.1023/A:1015450218211

Huczynski, A.A., \& Fitzpatrick, M.J. (1989). Managing employee absence for a competitive edge. London: Pitman Publishing.

Johnson, J. (2007). Absenteeism trends in South African companies - The biggest cause of absenteeism. Human Capital Review. Retrieved March 26, 2011, from http:// www.humancapitalreview.org/content/default.asp?Article_ID=578\&ArticleP

Joshi, K. (1989). The measurement of fairness or equity perceptions of management information systems users. MIS Quarterly, 13(3), 343-358. http://dx.doi. org $/ 10.2307 / 249010$

Khalifa, M.H.E., \& Truong, Q. (2010). The relationship between employee perceptions of equity and job satisfaction in the Egyptian private universities. Eurasian Journal of Business and Economics, 3(5), 135-150.

McKenna, E. (2000). Business psychology and organisational behaviour: A student's handbook. (3rd edn.). New York: Psychology Press.

Munro, L. (2007). Absenteeism and presenteeism: Causes and solutions. The South African Radiographer, 45(1), 21-23.

Northcraft, G.B., \& Neale, M.A. (1994). Organizational behavior: A management challenge. (2nd edn.). Fort Worth: Harcourt Brace College.

Riggio, R.E. (2009). Introduction to industrial/organisational psychology. New Jersey: Prentice Hall.

Slocum, J.W., \& Hellriegel, D. (2009). Principles of organizational behaviour. SouthWestern: Cengage Learning.

Stepina, L.P., \& Perrewe, P.L. (1991). The stability of comparative referent choice and feelings of inequity: A longitudinal field study. Journal of Organizational Behavior, 12(3), 185-200. http://dx.doi.org/10.1002/job.4030120303

Stevens, J. (1986). Applied multivariate statistics for the social sciences. Hillsdale, NJ: Lawrence Erlbaum.

Stokes, G. (2008). Managing sick leave. Retrieved June 18, 2010, from http://www. fanews.co.za/article.asp?Front_Page_Features;25;Straight_Talk;1146,Managing _sick_leave

Tabachnick, B.G., \& Fidell, L.S. (2007). Using Multivariate Statistics. New York: Allyn and Bacon.

Taylor, D.M., Moghaddam, F.M., Gamble, I., \& Zellerer, E. (2001). Disadvantaged group responses to perceived inequality: From passive acceptance to collective action Journal of Social Psychology, 127(3), 259-272. http://dx.doi.org/10.1080/00224 545.1987.9713692

Van Wyk, M.W. (2002). Conceptions of equality and social justice: A philosophical overview with reference to South Africa. Southern African Business Review, 6(2), 42-51.

Van Yperen, N.W., Hagedoorn, M., \& Geurts, S.A. (1996). Intent to leave and absenteeism as reactions to perceived inequity: The role of psychological and social constraints. Journal of Occupational and Organizational Psychology, 69, social constraints. Journal of Occupational and Organizational
367-372. http://dx.doi.org/10.1111/j.2044-8325.1996.tb00622.x

Weller, D.L. (1995). The equity factor: Avital part of the qualityequation. Quality Assurance in Education, 3(4), 44-50. http://dx.doi.org/10.1108/09684889510098186 